\title{
ANÁLISE DA DESIDRATAÇÃO DE RESÍDUOS DE PROCESSAMENTO DE MARACUJÁ (Passiflora Edulis) POR LIOFILIZAÇÃO
}

\author{
L.V. D. de FREITAS ${ }^{1}$, M. D. SILVA ${ }^{1}$, N. C. da $\operatorname{SILVA}^{1}$, C. R. DUARTE ${ }^{1}$ \\ e M. A. S. BARROZO ${ }^{1}$ \\ ${ }^{1}$ Universidade Federal de Uberlândia, Faculdade de Engenharia Química \\ E-mail para contato: luis_victor695@hotmail.com
}

\begin{abstract}
RESUMO - O Brasil é um dos maiores produtores frutíferos do mundo, e portanto, as indústrias brasileiras geram diariamente milhares de toneladas de resíduos desse processamento. Tais resíduos (sementes, cascas e bagaços) possuem diversas vitaminas e antioxidantes benéficos ao ser humano. Preocupantemente, esses resíduos são comumente descartados ou utilizados como ração animal, desperdiçando os compostos bioativos que poderiam ter mais adequado destino. Simultaneamente, o processo de desidratação tem se mostrado uma forma eficiente e econômica na conservação dos alimentos. A liofilização, é um recente processo que tem gerado excelentes produtos com baixos impactos em seus constituintes estruturais. Por conseguinte, o objetivo do seguinte trabalho é realizar a desidratação de resíduo de processamento de maracujá (Passiflora Edulis) através de um liofilizador convencional, verificando as variáveis tempo e método de congelamento e seus impactos na retirada de umidade e na concentração de compostos antioxidantes do material.
\end{abstract}

\section{INTRODUÇÃO}

O Brasil possui uma das maiores floras do planeta, graças a sua extensão territorial e variedade climática o que proporciona também uma biodiversidade ímpar. Consequentemente, é um dos líderes mundiais em produção de frutas, onde mais de $50 \%$ da produção é destinada ao processamento para a fabricação de polpas e sucos. O processamento das mesmas gera toneladas de resíduos que muitas vezes não são aproveitados, sendo simplesmente descartados ou utilizados como ração animal (Uchôa, 2007).

Tais resíduos possuem diversas substâncias benéficas e relevantes a nutrição do ser humano, como vitaminas e antioxidantes (Martínez et al., 2012), sendo assim, o reaproveitamento dos mesmos podem desencadear diversos proveitos em diversas áreas, como a possibilidade de otimização na produção das indústrias, a diminuição dos impactos ambientais causados pelo descarte dos resíduos, e até reduzir a fome, problema social que ainda persiste no Brasil.

A secagem, ou desidratação, vem sendo utilizada pelo homem há centenas de anos como forma de conservação de alimentos e atualmente, as técnicas avançaram de forma 
intensa. Diversos tipos de secadores foram criados com diferentes formas de secagem e seus impactos de formas mais variadas sobre a qualidade dos alimentos.

O resíduo proveniente do processamento do maracujá (Passiflora edulis) apresenta diversos nutrientes e compostos bioativos de extrema importância, além de uma notável quantidade de fibras solúveis e insolúveis, como a pectina, utilizada em alimentos, como geleificante, espessante, texturizante, emulsificante ou estabilizante (Bowers, 1992).

A liofilização é um método moderno e dispendioso de secagem e vem sendo utilizada em pequena escala no Brasil há mais de dez anos e Liofilizar consiste em remover toda a água através da sublimação a baixas pressões, e portanto, o alimento deve estar congelado (Terroni et al., 2013). Deste modo, o processo de liofilização deveria produzir alimentos de forma menos degradada que os demais métodos de desidratação e também apresenta a vantagem de pouca perda de aroma e sabor (Mujumdar, 1995).

Levando em consideração o exposto, este trabalho utilizou a técnica de liofilização para desidratação de resíduo oriundo do processamento de maracujá (Passiflora edulis), tendo como objetivo analisar a degradação dos compostos bioativos do mesmo após a secagem, avaliando sua viabilidade como método de reaproveitamento de tais resíduos.

\section{MATERIAIS E MÉTODOS}

O resíduo de maracujá (composto por cascas e sementes) foi fornecido pela empresa Lotus Soluções Ambientais, localizada na cidade de Araguari-MG. O material foi congelado através de dois métodos distintos: em freezer convencional, a temperaturas abaixo de $-5{ }^{\circ} \mathrm{C}$ por $24 \mathrm{~h}$ e em nitrogênio líquido, onde as amostras eram mergulhadas por um período de 15 minutos, até o completo congelamento. Foi utilizado um liofilizador convencional, da fabricante Liotop, modelo L-101, operando com $30 \times 10^{-3} \mathrm{mmHg}$ e temperatura de $-50^{\circ} \mathrm{C}$. Colocou-se uma massa de $120 \mathrm{~g}$ do resíduo para desidratar no equipamento, coletando-se as amostras nos períodos de $6,12,18,24,36,48,72$ e 120 horas. Após a desidratação verificouse a umidade do resíduo em estufa a $105^{\circ} \mathrm{C}$ por $24 \mathrm{~h}$ e analisou-se o impacto nos compostos bioativos.

Os compostos bioativos foram verificados (tanto do resíduo in natura quanto desidratado) através das seguintes análises físico-químicas(todas em triplicata): teor de Flavonóides Totais (determinado pelo método colorimétrico descrito por Zhishen et.al 1999 e expressos em $\mathrm{mg}$ de rutina/100 g de amostra em base seca), teor de Fenólicos Totais (determinado pelo método de Folin Ciocalteau Singleton \& Rossi, 1965 e expresso em mg de ácido gálico/100 g de amostra em base seca), teor de Acidez Total Titulável (ATT)(através da titulação com $\mathrm{NaOH}$ e expresso por $\mathrm{mg}$ de ácido cítrico/100 g de amostra em base seca AOAC, 1995) e teor de Ácido Ascórbico (AA) ou Vitamina C (obtido por titulometria, através da redução do 2,6-diclorofenol-indofenol, com os resultados expressos em $\mathrm{mg}$ de ácido ascórbico/100 g de amostra em base seca - AOAC, 1995).

\section{RESULTADOS E DISCUSSÕES}

Foram realizadas as análises para o resíduo in natura (antes da desidratação), que será utilizado como base de comparação, cujos resultados estão na Tabela 1: 
XI Congresso Brasileiro de Engenharia Química em Iniciação Científica Unicamp - Campinas - SP

Tabela 1 - Resultados para o Resíduo In Natura

\begin{tabular}{|c|c|}
\hline ANÁLISE & RESULTADO \\
\hline Umidade & $82,9 \pm 2,3 \%$ \\
\hline Teor de Flavonoides & $0,45 \pm 0,04 \mathrm{mg}$ rutina/ $100 \mathrm{~g}$ sólido seco \\
\hline Teor de Fenólicos & $122,13 \pm 9,35 \mathrm{mg}$ ácido gálico/100 $\mathrm{g}$ sólido seco \\
\hline Teor de Acidez & $2701,35 \pm 97,81 \mathrm{mg}$ ácido cítrico $/ 100 \mathrm{~g}$ sólido seco \\
\hline Teor de Vitamina C & $0,54 \pm 0,19 \mathrm{mg}$ ácido ascórbico/100 g sólido seco \\
\hline
\end{tabular}

Após as amostras serem liofilizadas durante os períodos de 6,12, 18, 24, 48, 72 e 120 horas realizou-se novamente as mesmas análises, para cada condição explicitada. As figuras a seguir representam os resultados:

Figura 1- Teor de Flavonoides (mg de rutina/100 g amostra seca)

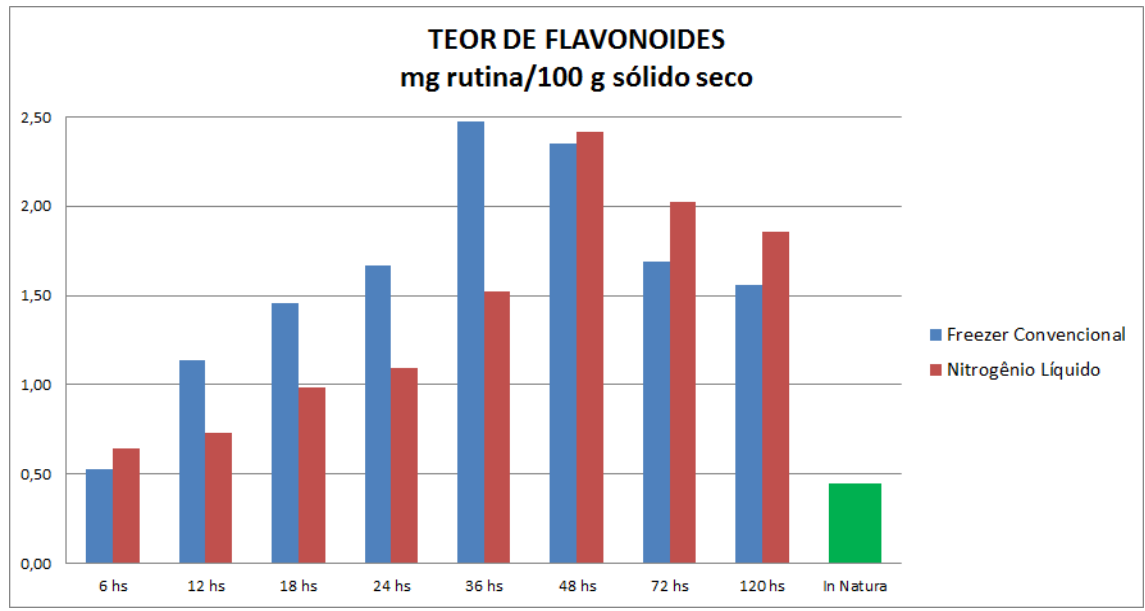

Figura 2 - Fenólicos (mg de ácido gálico/100 g amostra seca)

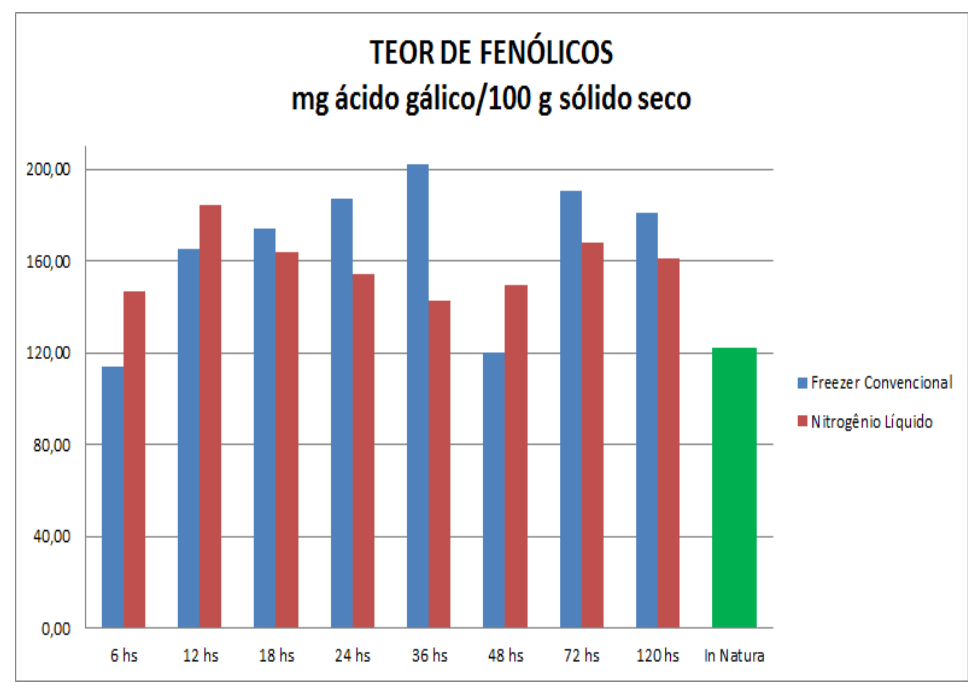




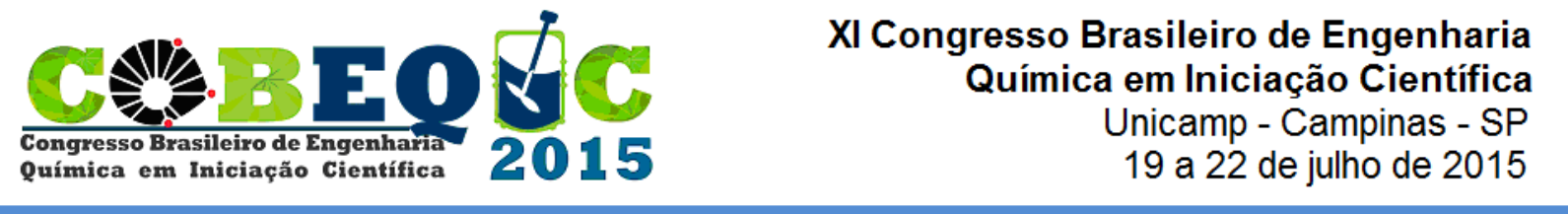

Figura 3 - Acidez (mg de ácido cítrico/100 g amostra seca)

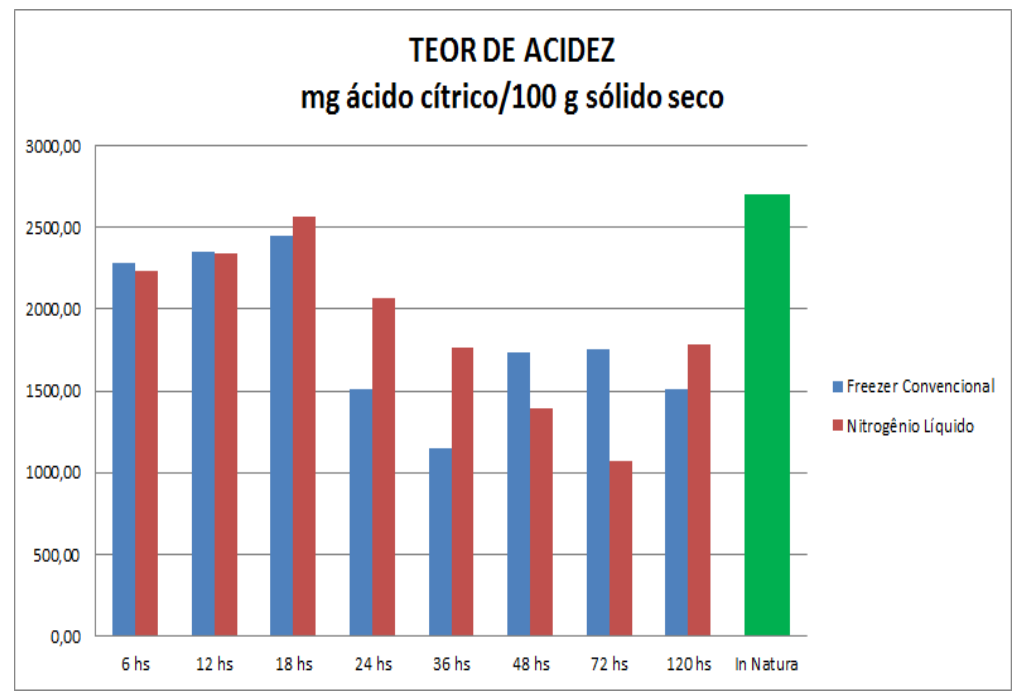

Figura 4 - Vitamina C (mg de ácido ascórbico/100 g amostra seca)

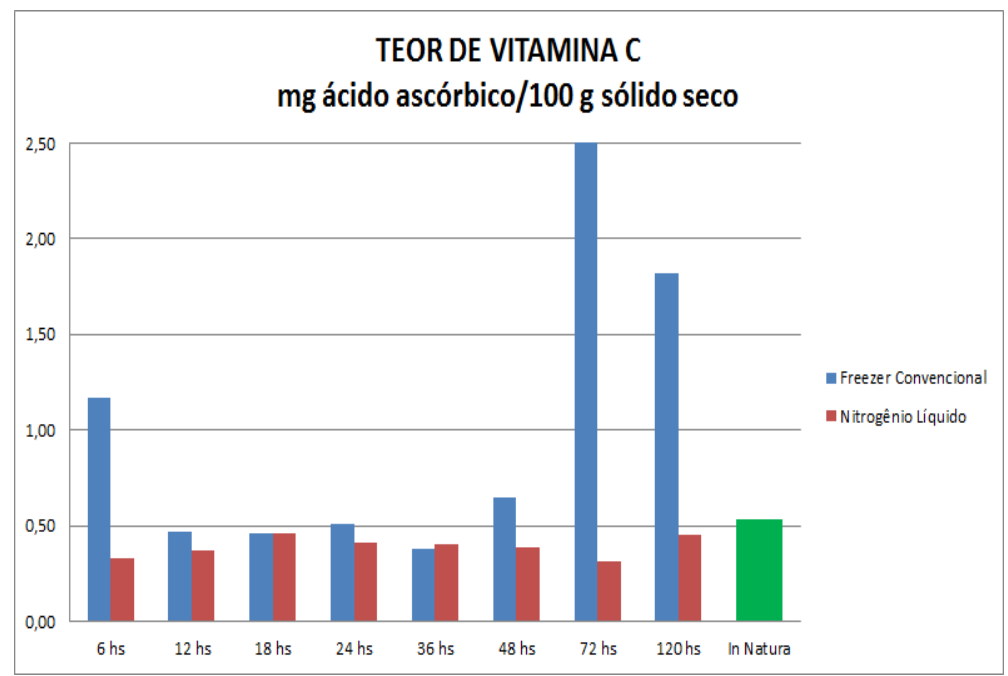

Os resultados apresentados na Figura 1 mostram que em ambos os métodos de congelamento, os teores de flavonoides se mantiveram mais altos do que do resíduo in natura durante todo o processo de liofilização, este aumento se dá pelo fato de que os compostos bioativos, antes aprisionados na estrutura, foram liberados ao longo da desidratação. Para a amostra congelada em freezer convencional, os teores se mantiveram mais altos do que da congelada por nitrogênio líquido até 36 horas de liofilização, passado este período, a amostra congelada por nitrogênio líquido apresentou valores maiores do que a congelada em freezer convencional.

Os teores de fenólicos também se mantiveram sempre maiores do que da amostra in natura, conforme a Figura 2, em ambos os métodos de congelamento os valores oscilaram, porém nas amostras congeladas em freezer convencional os teores se mantiveram maiores do que a congelada em nitrogênio líquido na maioria das análises. 
A acidez das amostras apresentou forte queda, conforme a Figura 3, em relação a amostra in natura, o que indica uma possível deterioração do ácido cítrico ao longo do processo. O maior valor obtido foi para 18 horas de liofilização, para os dois métodos de congelamento.

A vitamina $\mathrm{C}$, conforme a Figura 4, apresentou valores demasiadamente menores do que a amostra in natura, para os resíduos congelados em nitrogênio líquido, indicando também, uma brusca deterioração no ácido ascórbico. Para a amostra congelada em freezer convencional, os valores se mantiveram acima ou próximos do valor da amostra in natura, salve após 72 horas de liofilização, no qual os teores de vitamina $\mathrm{C}$ apresentaram imensa maximização.

Com os dados de umidade apresentados na Tabela 2 foi possível construir a curva de queda de umidade (\%) do material, representada pela Figura 5.

Tabela 2 - Resultados da secagem para os diferentes métodos de congelamento

\begin{tabular}{|c|c|c|}
\hline & \multicolumn{2}{|c|}{ UMIDADE (\%) } \\
\hline $\begin{array}{c}\text { Tempo } \\
\text { (horas) }\end{array}$ & $\begin{array}{c}\text { Freezer } \\
\text { convencional }\end{array}$ & Nitrogênio líquido \\
\hline 6 & 73,3751 & 78,8818 \\
\hline 12 & 67,6811 & 76,6101 \\
\hline 18 & 61,4401 & 72,7768 \\
\hline 24 & 52,0072 & 62,8272 \\
\hline 36 & 24,7740 & 47,6566 \\
\hline 48 & 6,0690 & 25,9537 \\
\hline 72 & 5,7156 & 11,1091 \\
\hline 120 & 3,0484 & 5,2875 \\
\hline
\end{tabular}

Figura 5 - Curva de Desidratação

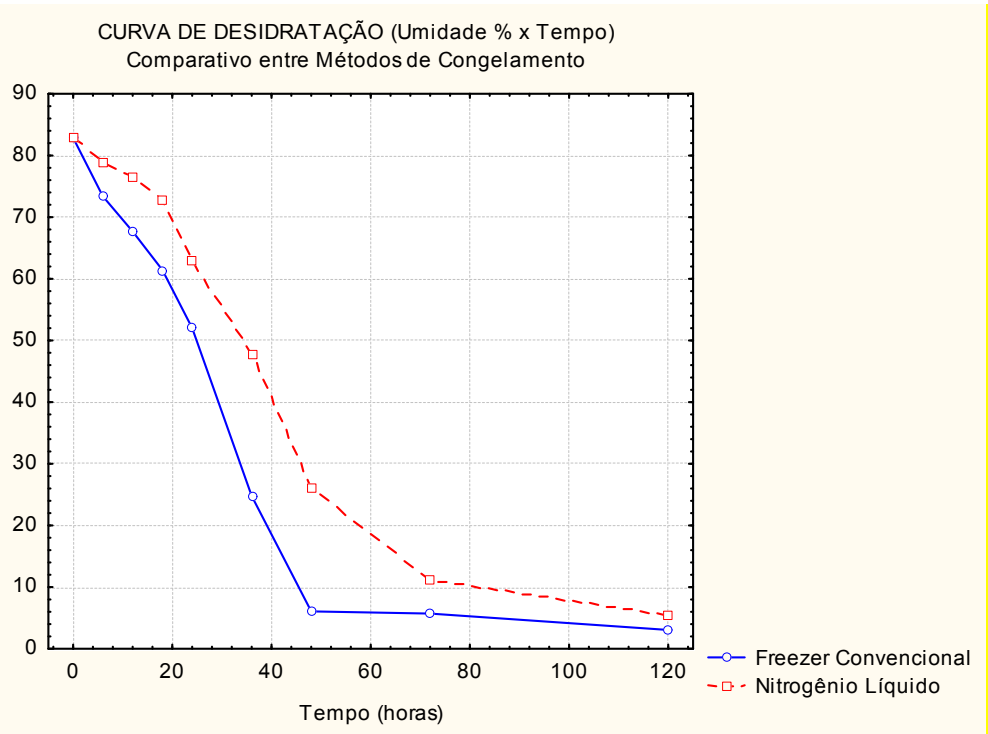


A desidratação em amostras congeladas em freezer convencional ocorreu de forma mais rápida do que em resíduos congelados em nitrogênio. Nas amostras congeladas em nitrogênio líquido, a retirada de umidade foi mais lenta do que em freezer convencional, isso se deve porque o rápido congelamento forma cristais de gelo pequenos o que diminui o fluxo de vapor durante a sublimação, aumentando o tempo de secagem. (Chaves et. al, 2009).

\section{CONCLUSÕES}

A liofilização do resíduo de maracujá se mostrou muito eficiente em relação a retirada de umidade nos dois métodos de congelamento (freezer convencional e nitrogênio líquido), em ambos os métodos observa-se também que nas primeiras 72 horas praticamente toda a umidade é retirada, nas seguintes horas a taxa de umidade cai lentamente, porém atinge significantes valores finais. Os teores de flavonoides e fenólicos se mantiveram acima dos teores da amostra in natura, porém a acidez e a vitamina $\mathrm{C}$ sofreram degradação. Por conseguinte, o método de congelamento por freezer convencional se mostrou mais eficiente no que diz respeito a conservação de todos os compostos bioativos analisados, salve flavonoides para longos tempos de desidratação.

\section{REFERÊNCIAS}

AOAC - Official Methods of Analysis Association of Official Analytical Chemists.

Gaithersburg, MD: Association of Analytical Communities, 1995;

BOWERS, J. Food Theory and Aplications. Second Edition. New York: Macmillan

Publishing Company, p. 411, 1992;

CHAVES, K. C. B.; MARQUES; L. G.; FREIRE, J. T. Determinação das Curvas de Congelamento em Freezer Convencional e Nitrogênio Líquido da Pimenta "Dedodemoça", p. 4, 2009;

MARTÍNEZ, R.; TORRES, P.; MENESES, M. A.; FIGUEROA, J. G.; PÉREZ-ALVÁREZ, J. A.; VIUDA-MATOS, M., Chemical, Technological and in vitro antioxidant properties of mango, guava, pineapple and passion fruit dietary fibre concentrate. Food Chemistry, v. 35, p. 1520-1526, 2012;

MUJUMDAR, A. S. Handbook of Industrial Drying, second edition v.1 pag.309-311, 1995.

ROS, J. M.; SCHOL, H. A.; VORAGEN, A. G. J., Lemon Albedo Cell Walls Contain

Distinct Populations of Pectic Hairy Regions. Carbohydrate Polymers, v. 37, p. 159-166, 1998;

SINGLETON, V. L \& ROSSI, J. A., Colorimetry of Total Phenolics with Phosphomolibidic Phosphotungistic Acid Reagents. American Journal of Enology and Viticulture, v. 16, p. 144-158, 1965;

TERRONI, H. C.; DE JESUS, J. M.; ARTUZO, L.T.; VENTURA, L. V.; SANTOS, R. F., "Liofilização" p. 1, 2013;

UCHÔA, A. M., Adição de Pós-Alimentícios Obtidos de Frutas Tropicais na Formulação de

Biscoitos. Dissertação de Mestrado, Universidade Federal do Ceará, CE, 2007;

ZHISHEN, J.; MENGCHENG, T.; JIANMING, W., The Determination of Flavonoid

Contents in Mulberry and Their Scavenging Effects on Superoxide Radicals. Food Chemistry, v. 64, p. 555-559, 1999. 